\title{
A 3D spatial data infrastructure for Mapping the Via Appia
}

\author{
Maurice de Kleijn $^{\mathrm{a}, *}$, Rens de Hond ${ }^{\mathrm{b}}$, Oscar Martinez-Rubi ${ }^{\mathrm{c}}$ \\ a Vrije Universiteit Amsterdam, Faculty of Economics and Business Administration, Spatial Information Laboratory (SPINlab), De Boelelaan 1105, \\ 1081 HV, Amsterdam, The Netherlands \\ ${ }^{\mathrm{b}}$ Radboud University, Faculty of Arts, Institute for Historical, Literary and Cultural Studies (HLCS), Erasmusplein 1, P.O. Box 9103, 6500 HD, \\ Nijmegen, The Netherlands \\ ${ }^{c}$ Netherlands eScience Center, Science Park 140, 1098 XG, Amsterdam, The Netherlands
}

\section{A R T I C L E I N F O}

\section{Article history:}

Received 2 September 2015

Received in revised form

22 January 2016

Accepted 26 March 2016

Available online 31 March 2016

\section{Keywords:}

3D GIS

Free and Open Source Software (FOSS)

3D Spatial Data Infrastructure

Reconstructions

Archaeology

Rome

\begin{abstract}
A B S T R A C T
The use of 3D technologies in archaeology and architectural history has grown enormously. Nowadays, 3D technologies are used to record, present, analyse and reconstruct archaeological sites. Since the used tools mostly originate from other domains, the developments are characterised as technology-driven rather than methodology-driven. The recent trend of Free and Open Source Software (FOSS) and the technological improvements of digital infrastructures are changing this.

This article presents the development of a 3D Spatial Data Infrastructure (3D SDI) that allows archaeology and historical architecture researchers to analyse complex sites. For the development of the 3D SDI, IT literacy levels of the users, reusability of the tooling and the advantages of using FOSS are taken into account. The 3D SDI was developed for Mapping the Via Appia. An interdisciplinary team of archaeology experts and engineers have developed tailor-made 3D solutions to enhance the analysis and exploration of the Via Appia.
\end{abstract}

(c) 2016 Elsevier Ltd. All rights reserved.

\section{Introduction}

Since the 1990s, the use of digital 3D technologies in archaeology and architectural history to study structures, sites and landscapes has grown considerably. Initially, these technologies were foremost used to present reconstructions. Looking back, these early virtual reconstructions are nowadays considered to have functioned more as illustration, rather than as coherent and scientifically transparent representations (Hermon, 2008; Frischer, 2008). This changed from the mid-2000s onwards with the introduction of advanced data capturing techniques, such as laser

\footnotetext{
The project is a collaboration between Radboud University, Vrije Universiteit Amsterdam, Royal Netherlands Institute in Rome (KNIR), and the Soprintendenza Speciale per $i$ Beni Archeologici di Roma (SSBAR). The project is funded by De Nederlandse Organisatie voor Wetenschappelijk Onderzoek (NWO) (Project number 380-61-001, 2011-2017) and the Netherlands eScience Center, (file number 027.013.901, 2012-2015). The development of the 3D SDI has started in 2011 and is led by the Spatial Information Laboratory (SPINlab) of the Vrije Universiteit Amsterdam, and conducted in collaboration with the Netherlands eScience Center and the Center for High Performance Computing and Visualisation of the Rijksuniversiteit Groningen.

* Corresponding author.

E-mail addresses: mtm.de.kleijn@vu.nl (M. de Kleijn), r.dehond@let.ru.nl (R. de Hond), o.rubi@esciencecenter.nl (O. Martinez-Rubi).

URLS: http://www.spinlab.vu.nl (M. de Kleijn),

http://www.ru.nl/hlcs/ (R. de Hond),

https://www.esciencecenter.nl/ (O. Martinez-Rubi).
}

scanning and photogrammetry methods, together with the development of advanced software to handle and analyse 3D data sets. This has allowed and stimulated archaeology and architectural history scholars to explore and incorporate these technologies in their research. Regarding the various ways in which 3D technologies are applied nowadays four different uses can be distinguished.

- First, 3D technologies are used to virtually analyse reality-based data derived from fieldwork such as excavations and architectural and field surveys. These 3D data can either be newly produced by measuring objects or excavated layers in the field using photogrammetry and laser scanning techniques, or derived from vectorised $2 \mathrm{D}$ field drawings from both recent and past documentation activities. A key advantage of collecting and converting fieldwork data in $3 \mathrm{D}$ is that it allows researchers to virtually analyse three-dimensional relationships between layers, structures and objects. Furthermore, real-world distances, dimensions and volumes can be virtually measured, as such tools are incorporated in most 3D software. Additionally, most 3D documentation initiatives have applied 2D GIS strategies as their starting point, meaning that archaeological units and architectural and archaeological objects are digitally and spatially defined, to which relational databases containing structured information are linked. For querying this attributive information, existing 3D GIS software (e.g. ArcScene) or custom made 
tools are used (Dell'Unto et al., 2015; Forte et al., 2012; Von Schwerin et al., 2013).

- The second use of 3D technologies distinguished is to produce digital archaeological and architectural 3D reconstructions. For producing 3D reconstructions, objects from reality-based models are virtually repositioned or additional objects are created based on the researcher's interpretation (e.g. Dell'Unto et al., 2013; Schäfer et al., 2015; Guidi et al., 2009; Piccoli, 2014).

- Advanced 3D spatial analyses such as calculating line of sight, flooding, smoke, noise and smell, as well as spatiotemporal analysis such as simulating shadows and astronomical relations, are distinguished as the third way in which archaeology and architectural history scholars use 3D technologies. Noteworthy studies are Johanson and Frischer (2008) and Frischer and Fillwalk (2013, 2014), in which hypotheses on alignments of reconstructed monuments to the sun have been tested in a virtual 3D environment, and the works by Paliou (2014) and Landeschi et al. (2016) on visibility analysis in reconstructed buildings.

- The fourth use of 3D technologies by archaeology and architectural history scholars is to present research results to other researchers and a broader audience. Already in the 1990s the value of 3D technologies for these purposes was noticed by Renfrew (1997). More recently, Frischer (2008) has stressed that computer modelling has become a standard application for archaeologists for presentation purposes. 3D technologies have also proved to be of value for educational purposes. The works of Forte et al. (2012) for Çatalhöyük and Liestøl (2014) alongside the Via Appia in Rome show interesting results on how virtual and augmented reality techniques can be used to present archaeological information to the public or archaeology students for educational purposes.

The various ways in which 3D technologies are used, as presented above, are strongly interwoven. Ideally one would use reality-based models as input for producing 3D reconstructions, applying basic measure and query tools as well as performing spatial and spatiotemporal analyses of them. The other way around, 3D reconstructions themselves can be used as input for advanced spatiotemporal analyses in order to test archaeological hypotheses, as demonstrated by Frischer and Fillwalk $(2013,2014)$. Furthermore, the sharing and presenting of results to other researchers and the use of 3D technologies for educational purposes require input from the previously mentioned uses.

However, although the archaeological and architectural history studies using 3D technologies have increased and evolved considerably, the currently available software tools and the required IT skills by the various users are considered to form a limitation in exploiting the possibilities of 3D technologies within these domains. Especially for the study of large-scale, complex, archaeologically rich areas, the number of suitable and reusable tools is currently limited. To that extend, the MayaArch3D project (URL 1; Von Schwerin et al., 2013; 2016; Auer et al., 2014) has produced valuable prototypes in which a large-scale archaeological site can be analysed in a virtual 3D environment. They produced a data infrastructure for the ancient Maya site of Copan in Honduras, which can be accessed, visualised and analysed through various applications. To enable sharing they have focussed their development on online tools. Preliminary results from that project show that it assists researchers in expanding questions and developing new analytical methods.

The current article presents a similar and even complementary approach to the MayaArch3D project by discussing the development and implementation of a 3D Spatial Data Infrastructure (3D SDI) for the Mapping the Via Appia project. In the context of this article we consider a SDI to exist of user objectives, user IT literacy, content (data), technical components and governance (see De Kleijn et al., 2014). Mapping the Via Appia aims to analyse the complex and archaeologically rich area between the fifth and sixth mile of the Via Appia (Mols et al., 2013; Mols, 2014; URL 2). The 3D SDI has been developed by an interdisciplinary team of software engineers, archaeologists and architectural historians (Netherlands eScience Center, Spatial Information Laboratory and Radboud University). The development of the presented 3D SDI differs from previous studies by focussing on working with Free and Open Source Software (FOSS) and using the GitHub platform (URL 3) to publish the produced code. This way, the study aims to demonstrate the possibilities and opportunities this paradigm shift in computer software development has to offer for archaeological and historical architectural studies in which 3D technologies are used. The article shows that issues regarding collecting data, sharing data, processing complex data sets and dealing with diverse skill levels and needs of users can be handled by developing a 3D SDI using FOSS. We believe that this direction offers a solution towards the issue sketched by Forte et al. (2012) that most 3D applications used within the discipline are technology-driven, rather than driven by archaeological research methodologies (Forte et al., 2012). Applying FOSS allows for user centric development of 3D software for the archaeological and architectural history domain. Furthermore, since FOSS are free to be reused by others and since the code is publicly available, the article aims to demonstrate that this approach lowers the financial barrier, an issue that has also been identified by Dell’Unto et al. (2015).

The article is structured as follows. After a description of the study area of Mapping the Via Appia and the specific opportunities for 3D technologies to be of value in the context of the project, the outcomes of a user requirement analysis are presented. This is followed by a description of the applied data acquisition and processing methods. Next, the architecture of the infrastructure, its relation to the data acquisition methods and the clients on top of it are presented. By discussing these steps and the components that have been developed, the article offers an insight into how 3D technologies can be applied for studying complex sites by various users by approaching it as a 3D SDI using FOSS.

\section{Case study: Mapping the Via Appia}

In the Mapping the Via Appia project, the area of the fifth and sixth miles of the Via Appia Antica is thoroughly investigated. The Via Appia is known as the queen of roads, running from Rome to Brindisi in the south of Italy. Its construction started in 312 BC. The road and its surroundings have seen many changes since then (Portella and Ventre, 2004). In antiquity the Via Appia had important commercial, military, religious and funerary functions, resulting in numerous funerary monuments, villas, farmsteads, sanctuaries and small industrial sites. When Rome fell into decay in the medieval period, so did the Via Appia. The area was used as quarry for high-quality building material. These activities destroyed significant parts of the ancient structures, which were often reused for new purposes. In the 19th century, the first few miles of the Via Appia from Rome were redecorated as an archaeological park. The remaining objects were arranged alongside the road as museum pieces, trees were added and - nowadays doubtful - reconstructions of ancient monuments were erected. Altogether these many changes have left us a complex multilayered landscape (Fig. 1).

The project has three research goals. The first goal is to gain an insight into the Roman interventions in this suburban landscape. The second goal is to understand what transformation the landscape has undergone after antiquity until the present day. The last aim is to gain an insight into the modern use of the archaeological 


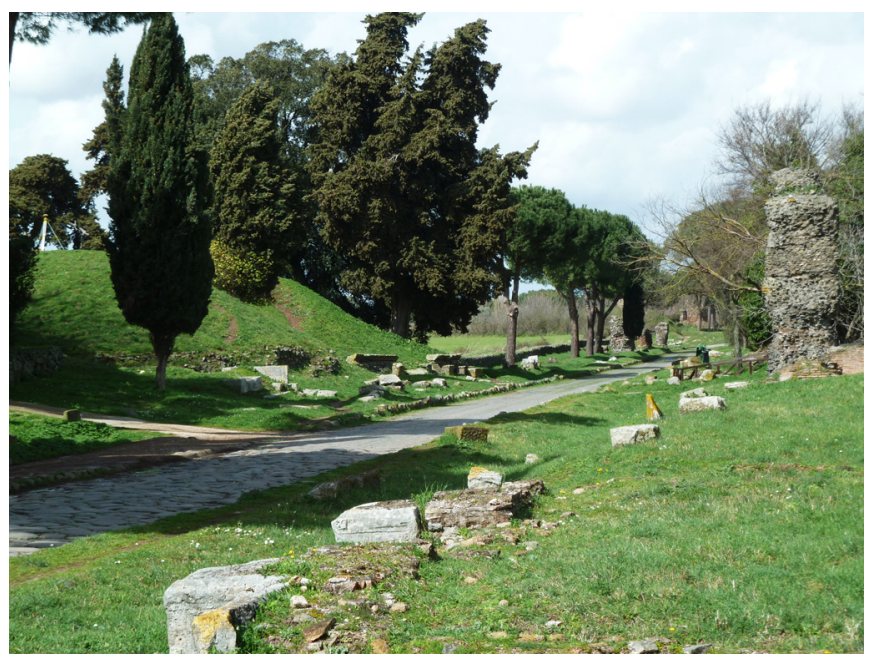

Fig. 1. The Via Appia Antica around the 5th mile from Rome (photo: Rens de Hond, 2013).

park and study opportunities to maintain and revitalise it.

In order to pursue these research goals, the researchers need to study previous historical architectural studies and analyse the archaeological remains in the current landscape and subsurface. To that end, various activities for Mapping the Via Appia are performed: i.e. excavations, archive studies, field surveys of the hinterland, documentation of the objects and structures adjacent to the road, remote sensing analyses using satellite images and historical aerial photographs and geophysical prospection surveys. In order to combine, share and analyse the various data sets derived from these different activities, a clear data management and infrastructure is of essence. For most of the data sets this is done using established technologies such as 2D GIS software and web sharing tools (i.e. QGIS, ArcMap, PostGIS and Openlayers). Although, 3D technologies to document and analyse excavation activities have proved to be of value (Dellepiane et al., 2012; Forte et al., 2012; Kooi, 2014), in the context of Mapping the Via Appia we apply traditional 2D GIS data documentation strategies, since the excavation is considered to be less complex compared to the abovementioned excavations. This could obviously be a follow-up on the present study. However, the above-ground ruins and fragments directly adjacent to the road are complex in shape, and essential details will not be captured when they are documented applying traditional $2 \mathrm{D}$ registration techniques. The density of this type of objects and structures is very high (approximately 2000 objects in the two-kilometre-long study area). Therefore, the urgency is felt to support this particular analysis process within Mapping the Via Appia with 3D technologies.

In order to understand how 3D technologies would aid the archaeology and architectural history researchers in studying the aboveground structures in the relatively large study area of Mapping the Via Appia, a user requirement analysis has been performed (of which the results have previously been published in De Kleijn et al., 2015). The key features that came out of this analysis are presented in Table 1.

Besides these requirements indicated by the intended users, we identified a high variety in the IT skill level of the users. We could make a distinction between users that want to explore the data sets, who on average have a relatively low IT skill level, and users that need to adjust and add new data sets (e.g. reconstructions), who on average are more used to working with advanced and complex software.

As for the visualisation and analysis of large and complex study areas in a virtual 3D environment area, no ready-to-use 3D tools
Table 1

User requirement analysis (after De Kleijn et al., 2015).

User requirements

(i) to be able to easily share the research results between the different team members of the project.4).

(ii) to be able to visualise a detailed reality-based model of the large study area and to perform accurate measurements on and between structures and objects. This means that various objects and structures needs to be integrated in one $3 \mathrm{D}$ viewer, that the measurements for the 3D data acquisition need to be accurate and that the user applications requires functionalities that allows the user to measure distances and volumes.

(iii) to be able to perform spatiotemporal analysis by querying the objects and structures based on attributive information (such as dating, type of decoration etc).

(iv) to be able to position historical images within the virtual 3D environment. Especially over the last three hundred years the Via Appia has been the subject of numerous paintings, drawings and photographs (Piranesi, 1756 ; Zocchi, 2009). Positioning these images within the virtual 3D environment allows archaeologists to analyse relatively recent changes within the landscape and the archaeological objects in it, but also how the road was perceived in more recent times.

(v) to be offered the possibility to integrate 2D GIS data. The various sub activities of Mapping the Via Appia generate two-dimensional GIS data like georeferenced historical maps, aerial photographs, vector excavation data, remote sensing data, and geophysics data. In order to compare these various sources, the 3D tools should be capable of integrating 2D GIS data based on their location.

(vi) to be able to export selections of the 3D data in order to use them in $3 \mathrm{D}$ modelling software allowing to generate $3 \mathrm{D}$ reconstructions and vice versa to allow newly produced reconstruction to be imported.

(vii) to have a system that can be used on the long term, that can be reused, and that allows to share knowledge with archaeology and architectural history researchers outside the research team

exist yet. The current study has therefore integrated existing tools, developing a tailor-made solution in line with the needs of the user group. Since the ability to easily share findings is one of the key requirements, we have approached the development of a 3D analytical tool as a 3D Spatial Data Infrastructure, storing the data on a server and users accessing the data through software clients. An additional advantage of this approach is that it allows the visualisation processing, which for visualising large and complex sites in high detail often hampers the user performance, to be supported by the computational properties of the server. Furthermore, approaching it as an infrastructure allows to develop clients in line with the various IT skill levels of the different types of users.

\section{Data acquisition and processing methods}

In order to obtain a detailed reality-based 3D model of the study area, we have applied the terrestrial LiDAR scanning technique DRIVE-MAP developed by Fugro (Kodde, 2010; URL 4). DRIVE-MAP is a dynamic laser scanning application that consists of a $360^{\circ}$ laser scanner, a panorama camera, a metric camera, a GPS, and accelerometers, all mounted on a car. The application produces a scaled and georeferenced coloured point cloud of the surrounding area in a relatively short time. In approximately 40 minutes the DRIVE-MAP application collected a point cloud, as LAS file format, of the road and its objects between the 5th and 6th mile of the Via Appia. Since the scanning device could only access the road, DRIVE-MAP did not give measurements of the rear sides of the archaeological objects. Considering the costs, in terms of both money and time, of applying terrestrial LiDAR scanning "manually", we obtained detailed 3D models for every individual object by using the image-based modelling technique Structure from Motion (SfM). To this end we used the open source tool SIFT for key point detection, Bundler for key point matching and 


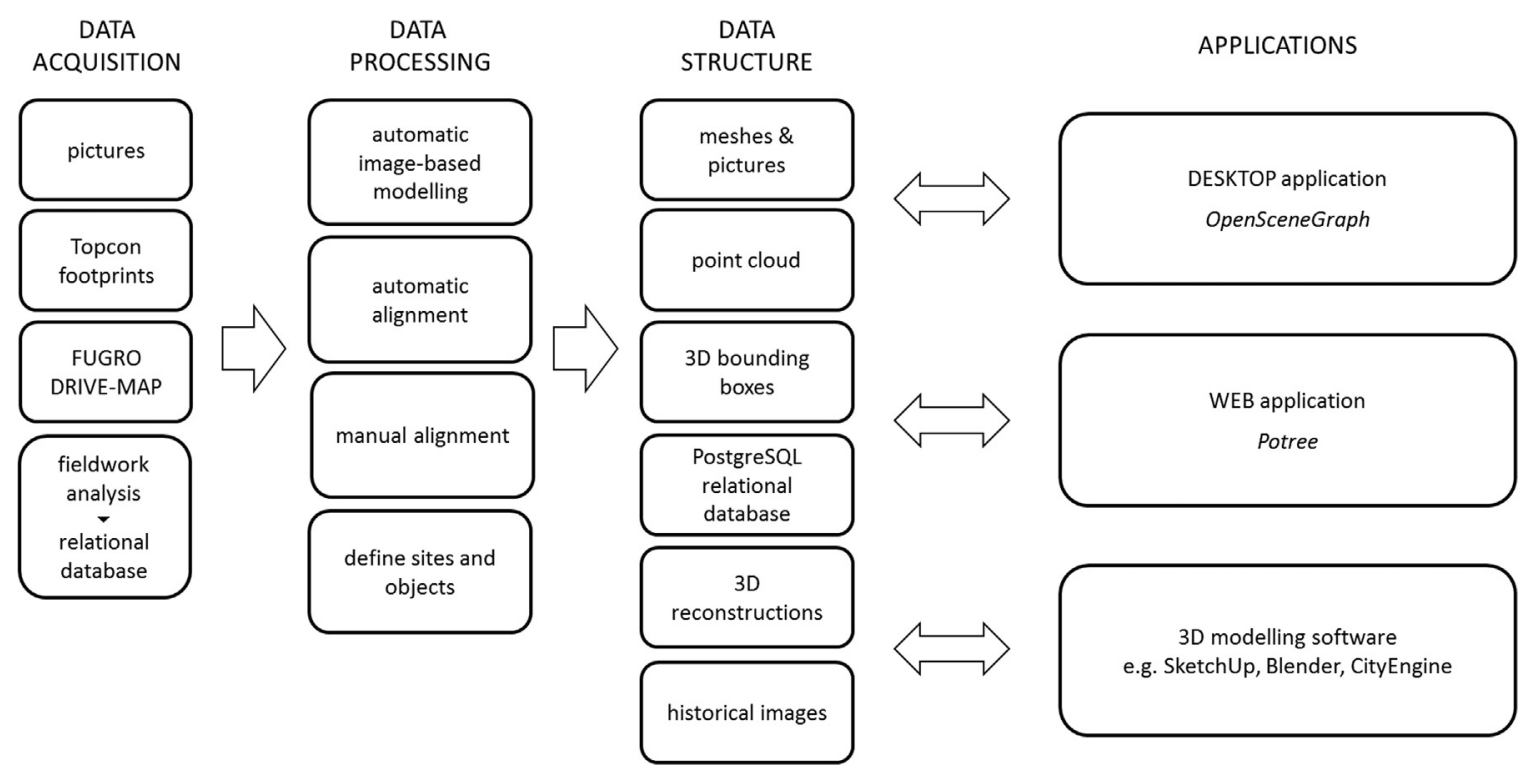

Fig. 2. Schematic overview of the 3D SDI to support the visualisation and analysis of above-ground structures and object for Mapping the Via Appia.

Clustering Views for Multi-view Stereo and Patch-based Multiview Stereo Software to generate 3D structures. This chain of tools produces a dense point cloud for every individual object, as LAS, which has been packed into a single script (URL 5; URL 6; URL 7). This allows users to automatically process multiple photosets at the same time. In addition to the point clouds, polyhedron models can be produced using poisson surface reconstruction algorithms from for example MeshLab. This is no part of the chain, but can be done "manually".

In order to integrate the SfM models into the 3D SDI these models need to be scaled and referenced to the earth surface. To do so, we collected the footprints of all archaeological objects and structures that are visible at the surface by using a differential GPS (TopCon HIPer Pro). These footprints have been stored as polygons and were all given a unique identification number (ID). Based on these footprints, a script has been developed which fully automates the process of aligning SfM output to the DRIVE-MAP point cloud. This alignment script goes through a chain which first filters the data, then scales it according to red and white rulers of which the exact length is known which are present in the pictures, and finally refers it by selecting a part of the DRIVE-MAP point cloud based on the footprints and relating the two subsets based on matching patterns. The script did not align all objects (approximately 50\%) and requires additional research and evaluation (more technical details on this process have been published on GitHub: URL 8). As an alignment of $100 \%$ seems not feasible, additional functionality to manually align the SfM data sets needs be implemented.

In order to query the objects based on characteristics noted in the field, a relational database has been developed. Characteristics like type of material, dating, decoration and construction technique have been filled into the database. By using the same ID as the footprints, the two of them can be integrated, enabling the system to perform spatiotemporal analyses.

\section{Description of the 3D spatial data infrastructure}

As detailed in the previous section, the data acquisition phase to obtain georeferenced reality-based models and attributive information on the characteristics from the objects and structures produced five different data sets: the footprint polygons, the relational database with attributive information of the different objects and structures, the reality-based DRIVE-MAP point cloud of the area seen from the road and the point clouds and polyhedral representations (meshes) of the individual objects generated using SfM methods. To allow simultaneous access to up-to-date data sets by multiple users with different goals and IT skill levels, the various data sets have been integrated as part of an online accessible 3D Spatial Data Infrastructure.

\subsection{The architecture}

At the core of the 3D SDI a server is configured containing the various data sets described above. To use the data sets for explorative and analytical purposes, two client applications are developed. The first application is a desktop tool meant for more skilled users to analyse, modify and upload newly produced 3D data. The second developed client application is a web tool developed for less IT literate users to access, explore and analyse the area in a virtual 3D environment. Although the two applications do contain significant GIS like functionalities, we prefer labelling them as desktop and web applications which are part of a 3D SDI, rather than calling them 3D GIS, a term that would, to some extent, be applicable as well. Additionally to the two mentioned applications, export functionalities have been developed, allowing the data to be used in 3D modelling software such as Blender, Sketch Up, Lumion 3D, 3D Studio Max or the procedural modelling software CityEngine, in which virtual 3D reconstructions can be generated. A functional architecture of the 3D SDI that aims to support the analysis process of the above-ground objects and structures alongside the Via Appia is provided in Fig. 2.

\subsection{The desktop application}

The desktop application is built using the already existing 3D viewer developed by the High Performance Computing and Visualisation department at the Rijksuniversiteit Groningen. This application uses components from the OpenSceneGraph (OSG) open source toolkit (URL 9) and has been modified for the purposes of Mapping the Via Appia (Video 1). In order to visualise the point cloud, the data needs to be converted to a native OSG format, which is done automatically by a conversion script. The code behind this application is, due to institutional legal issues, not publicly available. 


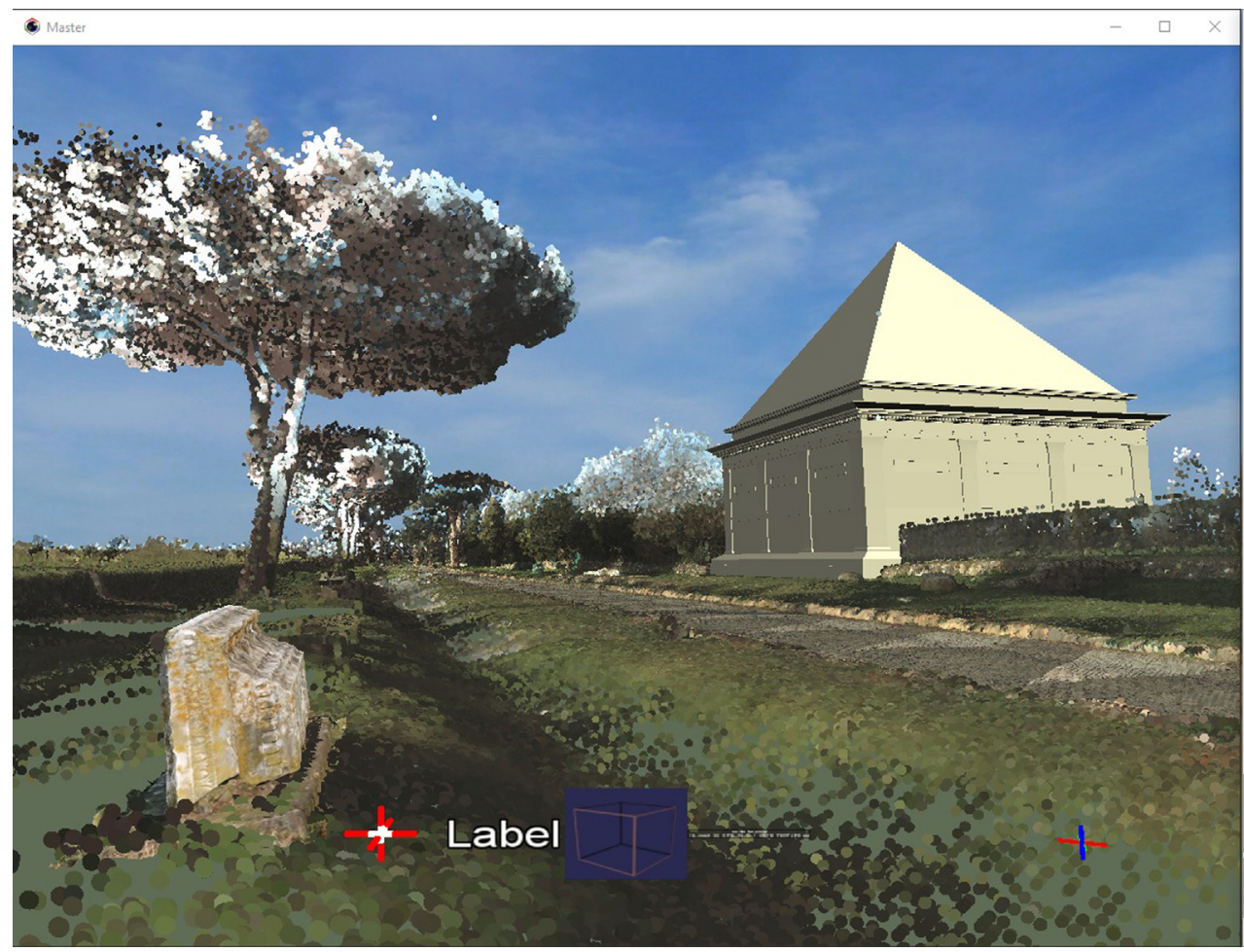

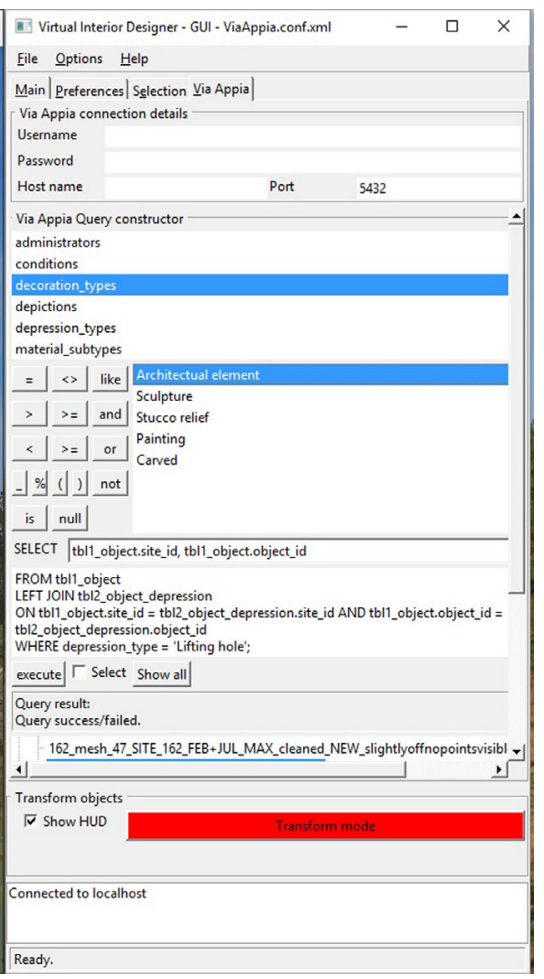

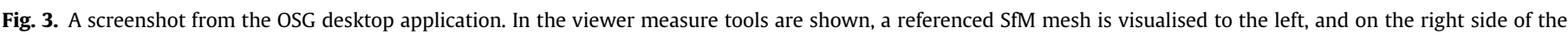

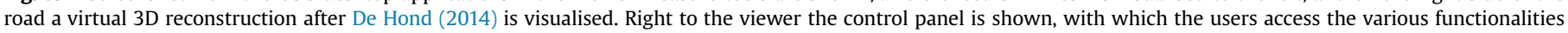
(e.g. querying, uploading and referencing the models).

The access to the data is based on remote synchronization. Before and after every session, a synchronization between the data on the local machine and the data on the server takes place. This method requires the user to reserve hard drive space on their local machines (approximately $40 \mathrm{~GB}$ ) and, depending on activities in other sessions and on the available internet connection bandwidth, sometimes takes a long time to complete. Additionally the user needs a computer that runs a recent 64-bit version of Windows (at least 7)

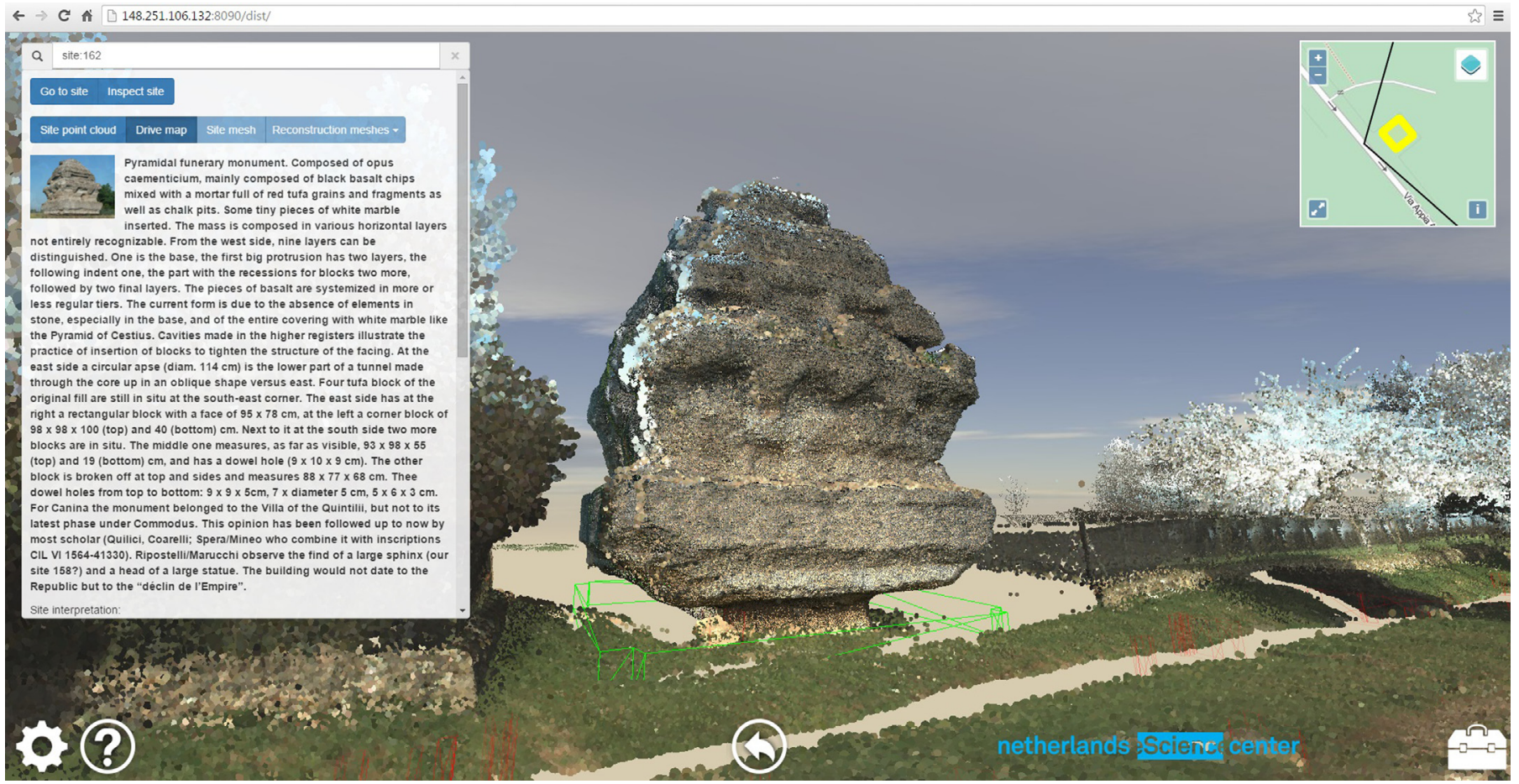

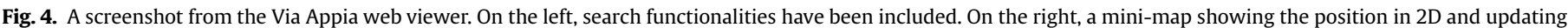
the queries formulated in the search bar. Icons in the left and right corner open measuring and configuration tools. 
with a relatively new video card. The OSG application allows the user to perform a variety of tasks. First, it offers functionality to analyse the area by allowing the user to query the data set based on dating and other characteristics registered and interpreted in the field. Second, the OSG application offers functionality to measure distances and volumes. Thirdly, the OSG application offers functionality to manually align the data, i.e. to manually align and scale image-based 3D objects to the DRIVE-MAP base point cloud. Polyhedral objects that have not been aligned and scaled with the alignment script described above can be manually processed with the tools offered by the desktop application. Additionally, this functionality allows newly generated archaeological reconstructions to be referenced in the virtual 3D environment (Fig. 3.). Fourthly, the application allows users to position images in the 3D environment. Historical paintings and pictures can be referenced as viewing windows with a fixed point of view, allowing the user to compare past views and perceptions to the present situation.

(Supplementary material related to this article can be found online at http://dx.doi.org/10.1016/j.daach.2016.03.001.)

\subsection{The web application}

The web application has been developed to allow the area to be explored, analysed and visualised in a virtual 3D environment through the internet without the user having to install additional software. The application consists of a 3D viewer, a search bar, a configuration pane, various measuring tools and a 2D mini map (Fig. 4; Video 2). Although functionality to visualise referenced historical paintings and photographs has been identified as one of the requirements for virtually exploring the area, it has not yet been developed, since it was considered to be technologically too complex. This would be something to develop as a follow-up. The web application works best on a relatively new computer with good graphic performance and using Google chrome as browser: at least above version 44.x. To visualise the point cloud data derived from both the DRIVEMAP and individual objects, in a web browser, the open source viewer Potree has been used and optimised. Potree has been selected after an extensive survey presented in Martinez-Rubi et al. (2015). Potree is based on the JavaScript API WebGL and uses the three.js JavaScript library (URL 10). It requires the point cloud data to be reorganised in an octree data structure that contains different levels of detail (LoD). This octree data structure defines nodes (virtual cubes), each containing eight equal children nodes (smaller cubes) and so on. By applying rules based on the distance to the user's viewpoint, the nodes of the octree in different LoDs that need to be streamed and displayed are efficiently selected, thus enabling the point cloud to be visualised in the user's web browser (URL 11; URL 12).

Supplementary material related to this article can be found online at http://dx.doi.org/10.1016/j.daach.2016.03.001.

The measurement tools for the Via Appia web application have been directly adopted from the Potree viewer. Potree contains functionalities to measure distances, angles, areas, volumes, offers functionalities to make cross-sections and to visualise sub-selections of the point cloud.

To allow users to analyse the various objects based on characteristics given in the field the Mapping Via Appia web application contains clickable bounding boxes around every object. By clicking the individual objects, the user can access the underlying database with the field recordings. Furthermore, a search bar has been included, making it possible to search for specific characteristics such as material, decoration or dating. The result of these queries is visualised as a clickable layer in the $2 \mathrm{D}$ mini map, making it possible for the user to navigate to it in 3D. The bounding boxes around the objects also allow the user to switch to the more detailed SfM point clouds of the individual objects. Visualising all
SfM point clouds from every object in combination with the DRIVEMAP data appeared to be too much, severely lagging the viewer's performance.

The 2D mini map has been developed using the open source JavaScript library OpenLayers. Besides the footprints and various base maps, the 2D map includes relevant historical maps from the study area using Web Mapping Services (WMS) provided by the VU University Geoplaza Spatial Data Infrastructure (URL 13). Furthermore, this mini map allows to integrate 2D data sets derived from the other archaeological activities performed in the context of Mapping the Via Appia (i.e. vector data connected to relational databases from excavation and field survey activities), when published according to OGC standard mapping service protocols like WMS or Web Feature Services (WFS) (URL 14).

\subsection{D-HOP integration}

To enhance the online visualisation of individual objects, the Potree web application has been extended with the open source online presenter software 3D-HOP developed by the Visual Computing Laboratory - ISTI - CNR (Potenziani et al., 2015; URL 15), allowing the web visualisation of meshes. When clicking an individual object in the web application, the user can choose between visualising the point cloud model and the mesh. The point cloud is shown in the Potree viewer, whereas the polyhedral model visualisation appears in a separate interface. One of the main advantages of the polyhedral model visualisation using 3DHOP is that it offers analytical functionalities to change the light settings. Users can change the angle and direction of the light, which is useful in the process of interpreting inscriptions and decoration types. Since the point clouds do not have any surfaces, this would not have been possible. Another advantage of using 3DHOP is that meshes look more realistic than point clouds. However, since these models are produced by interpolating surfaces between point clouds, it might on the other hand also introduce errors. Users should be aware of what they are using and what they are looking at (Fig. 5).

\section{Discussion}

Considering the user requirements for a virtual 3D environment to study a large and complex archaeological landscape full of above-ground archaeological objects and structures, as formulated in Section 2, the presented 3D SDI is considered to have answered to most of them. Additionally, by working with FOSS, this article demonstrates the opportunities this paradigm shift in software development has to offer for archaeology and architectural history studies aiming to use 3D technologies to support the process of analysing complex sites.

As for acquiring a detailed reality-based 3D model of a complex study area (user requirement ii), this study demonstrates that the SfM FOSS tools are of great value, but that in order to scale and reference them with high precision, sophisticated sensors are required. Furthermore it shows that developments in openly available pattern recognition algorithms offer clear opportunities for automating the processing of referencing objects, but that manual interference is still required.

As for sharing (user requirement i) and dealing with various users with different IT-skill levels the technologies used for Mapping the Via Appia have been approached as an infrastructure containing two user applications. The web application has been developed for all types of users. This application is considered to be easy to use, but it is limited to visualising, exploring and analysing the area, without having capabilities to change or add data. The desktop application, on the other hand, requires more skills 


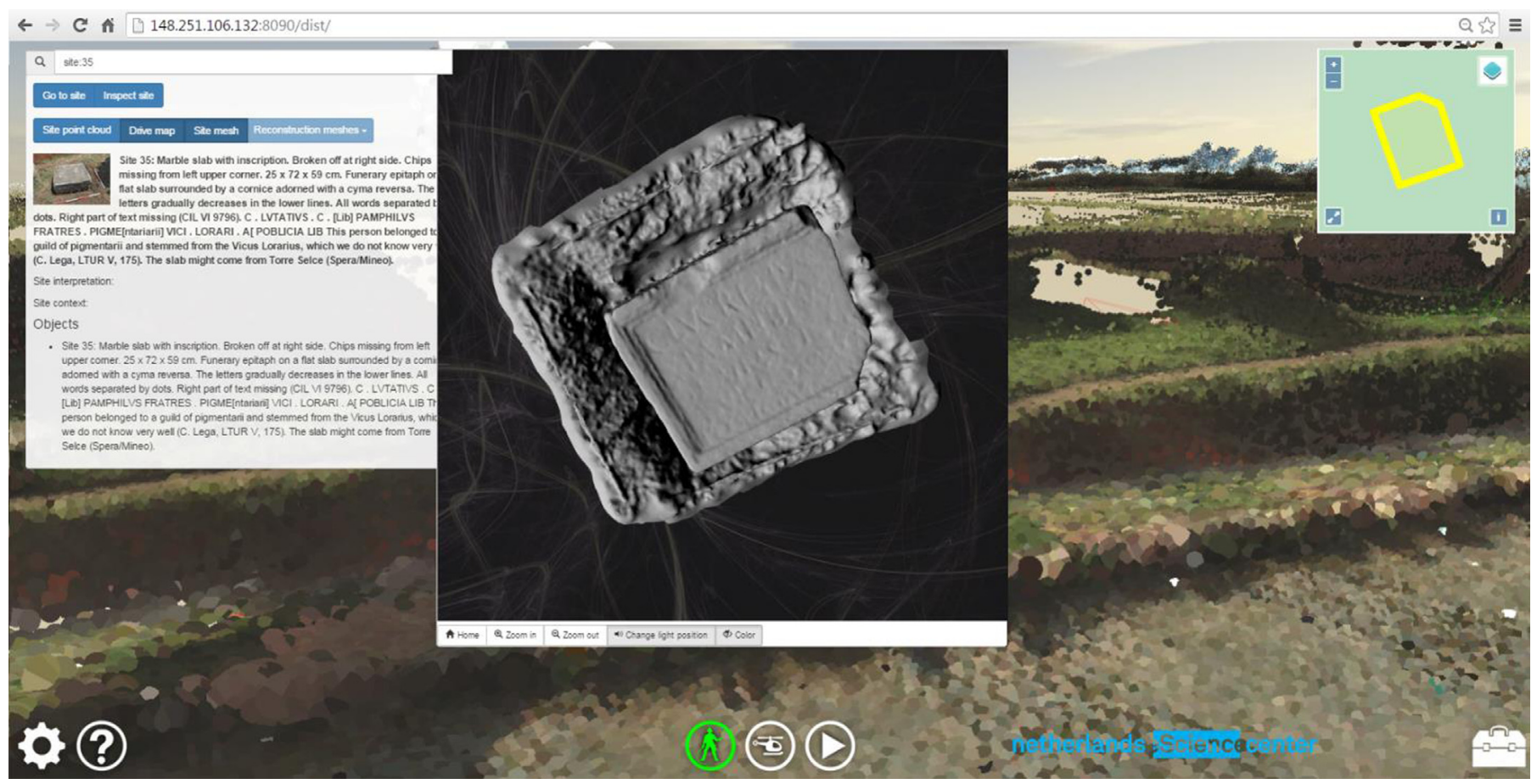

Fig. 5. Integration of 3D-HOP with the Via Appia web viewer.

Table 2

An overview of the user requirements confronted with the solutions offered by the desktop and web application.

\begin{tabular}{|c|c|c|}
\hline User requirements & Desktop application & Web application \\
\hline
\end{tabular}

(i) to be able to easily share the research results between the difsignificant disk space

(ii) to be able to visualise a detailed reality-based model of the large study area and to perform accurate measurements on and between structures and objects. This means that various objects and structures needs to be integrated in one 3D viewer, that the measurements for the 3D data acquisition need to be accurate and that the user applications requires functionalities that allows the user to measure distances and volumes.

- Visualising complex 3D landscapes

- Measure tools

Aquiring and processing high accurate reality-based model

(iii) to be able to perform spatiotemporal analysis by querying the objects and structures based on attributive information (such as dating, type of decoration etc).

(iv) to be able to position historical images within the virtual 3D environment. Especially over the last three hundred years the Via Appia has been the subject of numerous paintings, drawings and photographs (Piranesi, 1756; Zocchi, 2009). Positioning these images within the virtual 3D environment allows archaeologists to analyse relatively recent changes within the landscape and the archaeological objects in it, but also how the road was perceived in more recent times.

(v) to be offered the possibility to integrate 2D GIS data. The various sub activities of Mapping the Via Appia generate two-dimensional GIS data like georeferenced historical maps, aerial photographs, vector excavation data, remote sensing data, and geophysics data. In order to compare these various sources, the 3D tools should be capable of integrating 2D GIS data based on their location.

(vi) to be able to export selections of the 3D data in order to use them in 3D modelling software allowing to generate 3D reconstructions and vice versa to allow newly produced reconstruction to be imported.

and practice to use and is developed for more IT literate users. Regarding the user requirements related to capabilities and functionalities of the 3D clients an overview is provided in Table 2.
Since the 3D SDI developed for Mapping the Via Appia is meant to serve the archaeology and architectural history researchers involved for the upcoming years, user requirement vii, the 
availability of the tools and data produced in the project, including newly produced $3 \mathrm{D}$ reconstructions, on the long term is seen as a significant thread. Considering this thread four aspects have to be taken into account. The first aspect issues the governance of the 3D SDI, this considers things like where the SDI is hosted and who pays for the server costs and is responsible for the maintenance. During the project this is not be seen as a problem, since server expenses and personnel costs are covered. However, after the project's funding is finished this will be problematic, since budget is required to pay for server costs and experts need to remain involved to maintain the server. The second aspect concerns the technological durability of the tools. A clear example in which this thread has become reality is the "Via Appia Antica"- project (Forte et al., 2005; Calori et al., 2005). The technologies used in that project are nowadays outdated. However, this goes beyond the capabilities and influence of an individual project, since this depends on web standards and web protocols like HTML5 formulated by the World Wide Web Consortium (WC3; URL 16). To that extent it is advisable to work according such standards. The third issue is about the data format. In order to allow reuse of the data, they need to be stored in an interoperable format. For Mapping the Via Appia the LAS file format has been used for the point cloud and PLY and OBJ format for the polyhedral models. The fourth issue considers the data model on the content of the data making them content wise interoperable (De Roo et al. 2014). For the 3D reconstructions that have so far been produced in the context of Mapping the Via Appia, the London Charter framework has been applied in the form of a written report (URL 17; Denard, 2012; De Hond, 2014). A future development in that regard might be to integrate the London Charter in the 3D models themselves and formulate a standardized 3D data model. This would foster scientific data transparency allowing to interactively explore and access the reconstructions.

In order to face these issues, clear documentation strategies, standards and long term viability plans are essential. To that extent involvement of local institutions such as university libraries, national institutes for storage of scientific archaeological data such as Data Archiving and Networked Systems (DANS; URL 18) and the archaeological agency (i.e. SITAR, Serlorenzi and De Tommasi, 2010), or EU-funded initiatives and networks such as 3D icons (URL 19) and ARIADNE (URL 20) are considered to play an essential role.

\section{Conclusions}

This article has shown to develop a 3D system, a 3D SDI, that facilitates archaeological and architectural history research to explore, analyse and reconstruct complex archaeological landscapes full of structures and objects of interest. The presented 3D SDI has been developed in close collaboration with the intended users. It offers solutions to enhance easy sharing of archaeological scientific data and knowledge, offers innovative analytical functionalities for conducting spatiotemporal analyses in large scale areas, allows to deal with issues on IT-literacy by the development of various applications for differently skilled users and allows to integrate other spatial data services, such as Geoplaza, and 3D visualisation tools, such as 3D-HOP, making combining and comparing multiple data sources possible. Although the first researchers that have used the system have already pointed out its usefulness, the upcoming years will show us how the system will actually be used and how it will facilitate the archaeological analyses.

Except for the desktop application, all tools and applications that have been developed are published as FOSS on the online platform Github accompanied by a clear documentation (URL 5, URL 6, URL 7, URL 8, URL 11, URL 12). The article has therefore demonstrated that the changing paradigm towards FOSS in software development offers matured components with which tailor-made useful 3D interfaces can be developed for the archaeological and architectural history domains. By publishing the newly produced software on Github, we also allow others to reuse the tools we developed. We therefore believe that this study demonstrates that we are at a turning point, putting 3D technologies to archaeologically and architectural history methodologically driven uses.

Reflecting on the various uses of 3D technologies in archaeology and architectural history studies, as presented in the introduction, (basic analysis for analysing reality based model, generating academic grounded 3D reconstructions, performing advanced 3D analyses and presenting research results to a broader public and for educational purposes) it is clear that the various software tools used by different research teams is highly heterogeneous, complicating the reuse of tools for other purposes. By using FOSS making the code available to the public domain, we believe that tools can be easily reused, resulting in tailor-made solutions in line with the various purposes and needs of the archaeological and architectural history research community. Ideally this would lead to libraries of tools where users would be able to configure interfaces with required functionalities for their purposes. Approaching it as such would make it for example possible to combine querying capabilities with analytical functionalities developed in the context of other future projects, or allow educational story telling tools, as develop by Liestøl (2014), to be built on top of the tools developed for Mapping the Via Appia.

However, as stressed by Von Schwerin et al. (2013), Dell'Unto et al. (2015) and Forte et al. (2012), an obstacle remains that 3D digital research tools can currently not be developed without significant budgets and the participation of skilled software and database engineering researchers. Like the MayaArch3D project, Mapping the Via Appia could also rely on strong technological partners and a significant budget. Although funding structures have also changed accordingly, stimulating interdisciplinary research projects, these requirements can be significant obstacle for other research teams. We expect this obstacle to remain present for the upcoming years, but believe that the trend of using FOSS and publishing newly produced codes online can change this. Mapping the Via Appia must therefore be seen as one of the first projects in this field to do so. We therefore strongly advocate our approach and invite other research teams to work accordingly. This allows archaeology and architectural history research teams to build on each other's knowledge and develop robust and useful 3D tooling specifically for their domain.

The main thread for Mapping the Via Appia is the long term viability of the tools and data. Resolving this issue goes beyond the control of a single project and requires standards and strong leadership from local and governmental institutes. Fortunately, major current infrastructural projects such as ARIADNE and 3D Icons are contributing in formulating standards and are functioning as 3D repositories of individual structures and sites.

\section{Acknowledgements}

The authors wish to first thank the anonymous reviewer for their valuable feedback to our work. Furthermore we wish to thank the following persons and institutes. The staff from Mapping the Via Appia and the archaeological agency of Rome (Soprintendenza Speciale per $i$ Beni Archeologici di Roma, especially Dott.ssa Rita Paris and Dott.ssa Antonella Rotondi). From the SPINlab: Henk Scholten, Eduardo Dias and Simeon Nedkov. The Netherlands eScience engineers for the valuable work they have done to develop the various tools: Maarten van Meersbergen, Stefan Verhoeven, Jisk Attema, Rob van Nieuwpoort, Ben van 
Werkhoven, Milena Ivanova, Patrick Bos, Romulo Pereira Gonçalves, Christiaan Meijer, Elena Ranguelova, Carlos Mertinez-Ortiz, Janneke van der Zwaan, Jurriaan Spaaks, Jason Maassen, Joris Borgdorff, Parisa Noorishad, Niels Drost, Mateusz Kuzak and Ronald van Haren. From the HPC\&V: Frans van Hoesel and Pjotr Svetachov. The company FUGRO. The CNR-ISTI and the ARIADNE programme for allowing our team to participate in the $2 \mathrm{D} / 3 \mathrm{D}$ documentation for archaeology' summer school. All participating students, in particular Frank Beijaard, Joey van Kuijck and Tim Pijls. Finally, the authors thank Azarakhsh Rafiee and Stefan Kooi for their valuable feedback on our work.

Access to the web viewer

Although the tools have been developed using FOSS, the Via Appia data themselves are not in the public domain due to legal restrictions. For access to the web viewer, the reader can contact the corresponding author. Some of the tools developed for Mapping the Via Appia have been reused and extended to visualise the open data LiDAR point cloud data set of the Netherlands (approximately $1.6 \mathrm{~TB}$ in compressed form), which can be accessed via URL 21 (Martinez-Rubi et al., 2015).

\section{References}

Auer, M., Agugiaro, G., Billen, N., Loos, L., Zipf, A., Web-based Visualization and Query of semantically segmented multiresolution 3D Models in the Field of Cultural Heritage In: ISPRS Ann. Photogramm., Remote. Sens. Spat. Inf. Sci. II-5 20143339 http://dx.doi.org/10.5194/isprsannals-II-5-33-2014.

Calori, L., Camporesi, C., Forte, M., Pescarin, S., 2005. VR WebGIS: an OpenSource approach to 3D real-time landscape management, International Conference Virtual City and Territory (2n: 2005: Concepción). Laboratorio de Estudios Urbanos, Universidad del Bío-Bío.

De Hond, R.J.F., 2014. A Pyramidal Structure along the Via Appia. Documentation and reconstruction. Radboud University Nijmegen, unpublished.

De Kleijn, M., van Manen, N., Kolen, J., Scholten, H., 2014. Towards a User-centric SDI framework for historical and heritage european landscape research. International Journal of Spatial Data Infrastructures Research 9, 1-35. http://dx.doi.org 10.2902/1725-0463.2014.09.art1.

De Kleijn, M.T.M., De Hond, R.J.F., Martinez-Rubi, O., Svetachov, P., 2015. A 3D Geographic In-formation System for 'Mapping the Via Appia', Research Memorandum (VU-FEWEB) 2015-1, Amsterdam.

Dellepiane, M., Dell Unto, N., Callieri, M., Lindgren, S., Scopigno, R., 2012. Archeological excavation monitoring using dense stereo matching techniques. Journal of Cultural Heritage 2012. http://dx.doi.org/10.1016/j.culher.2012.01.011.

Dell'Unto, N., Leander, A.M.,Ferdani, D., Dellepiane, M., Callieri, M., Lindgren, S., 2013. Digital reconstruction and visualization in archaeology: Case-study drawn from the work of the Swedish Pompeii Project. In: Proceedings Digital Heritage International Congress (DigitalHeritage), vol. 1.

Dell`Unto, N., Landeschi, G., Leander Touati, A.-M., Dellepiane, M., Callieri, M., Ferdani, D., 2015. Experiencing ancient building from a 3D GIS perspective: a case drawn from the Swedish Pompeii Project. Journal of Archaeological Method Theory, January 2015, Springer.

Denard, H., 2012. A New Introduction to The London Charter. In: Bentkowska-Kafel, A., Denard, H., Baker, D. (Eds.), Paradata and Transparency in Virtual Heritage. Ashgate, Farnham, pp. 57-71.

De Roo, B., Ooms, K., Bourgeois, J., De Maeyer, P. (2014). Bridging archaeologu and GIS: influencing factors for a 4D archaeological GIS 5th International Conference, EuroMed, Limassol, Cyprus, November 3-8, 2014. In: Ioannides, M. Magnenat-Thalmann, N., Fink, E., Žarnić, R., Yen, A., Quak, E. (eds.), Proceedings Digital Heritage. Progress in Cultural Heritage: Documentation, Preservation, and Protection Volume 8740 of the series Lecture Notes in Computer Science. Springer. pp. 186-195.

Frischer, B., 2008. From digit al illustration to digital heuristics. In: Frischer, B. Dakouri-Hild, A. (Eds.), Beyond Illustration: 2D and 3D Digital Technologies as Tools for Discovery in Archaeology. British Archaeological Reports International Series, pp. v-xxii.

Frischer, B., Fillwalk, J., 2013. A computer simulation to test the Buchner thesis: the relationship of the Ara Pacis and the Meridian in the Campus Martius, Rome. Digital Heritage International Conference (Digital Heritage) (IEEE 2013) vol. 1, 341-345. http://dx.doi.org/10.1109/DigitalHeritage.2013.6743758.

Frischer, B., Fillwalk, J., 2014. New Digital Simulation Studies on the Obelisk, Meridian, and Ara Pacis of Augustus. In: Haselberger, L., (Ed.). The Horologium of Augustus: Debate and Context, Journal of Roman Archaeology Supplementary Series Number 99 (2014) 77-90.

Forte, M., Pescarin, S., Pietroni, E., 2005. The Appia antica project. In: Forte, M. (ed.) The reconstruction of Archaeological Landscapes through Digital Technologies. In: Proceedings of the 2nd Italy-United States Workshop. Rome, Italy,
November 3-5, 2003. Berkeley, USA, May. BAR International series 1379, pp. 79-91.

Forte, M., Dell'Unto, N., Issavi, J., Onsurez, L., Lercari, N., 2012. 3D Archaeology at Çatalhöyük. International Journal of Heritage in the Digital Era 1 (3).

Guidi, G., Remondino, F., Russo, M., Menna, F., Rizzi, A., Ercoli, S., 2009. A multiresolution methodology for the 3D modeling of large and complex archeological areas. International journal of architectural computing issue 0107 (01).

Hermon, S., 2008. Reasoning in 3D: a critical appraisal of the role of 3D modelling and virtual reconstructions in archaeology. In: Frischer, B., Dakouri-Hild, A (Eds.), Beyond Illustration: 2D and 3D Digital Technologies as Tools for Discovery in Archaeology. British Archaeological Reports International Series, pp. 35-44.

Johanson, C., Frischer, B., 2008. A digital model in the Inca sanctuaryof the sun. In: Frischer, B., Dakouri-Hild, A. (Eds.), Beyond Illustration: 2D and 3D Digital Technologies as Tools for Discovery in Archaeology. British Archaeological Reports International Series, pp. 35-44.

Kodde, M., 2010. The art of collecting and disseminating point clouds. In: Van Oosterom, P.J.M., Vosselman, M.G., Van Dijk, Th.A.G.P., Uitentuis, M. (Eds.), Management of massive point cloud data: wet and dry. Netherlands Geodetic Commission, Delft, p. 49.

Kooi, S., 2014. 3-D documentation of archaeological field data using free, opensource modelling software. Pharos 20-2, 99-119.

Landeschi, G., Dell'Unto, N., Lundqvist, K., Ferdani, D., Campanaro, D.M., Leander Touati, A.-M., 2016. 3D-GIS as a platform for visual analysis: investigating a Pompeian house. Journal of Archaeological Science, 103-113, Elsevier.

Liestøl, G., 2014. Along the Appian Way. Storytelling and Memory across Time and Space in Mobile Augmented Reality In: Digit. Herit. Progress. Cult. Herit.: Doc. Preserv. Prot. 8740, 248-257.

Martinez-Rubi, O., Verhoeven, S., Van Meersbergen, M., Schütz, M., Van Oosterom, P., Gonçalves, R., Tijssen. T., 2015. Taming the beast: Free and open-source massive point cloud web visualization, In proceedings, Capturing reality, 3D laser scanning \& LiDAR technologies forum, 23-25 November Salzburg, Austria.

Mols, S.T.A.M., Moormann, E.M., Pelgrom, J., 2013. Mapping the Via Appia. Tijdschrift Mediterrane Archeologie 50, 86.

Mols, S.T.A.M., 2014. Mapping the Via Appia. Forma Urbis XIX (9), 38-41, Rome.

Paliou, E., 2014. Paliou, E., Lieberwirth, U., Polla, S. (Eds.), Visibility analysis in 3D build spaces: a new dimension to the understanding of social space. Spatial Analysis and Social Spaces, Berlin/Boston.

Piccoli, C., 2014. 3D reconstruction techniques as research tolls in archaeology: the case study of Koroneia, Greece. Tijdschrift Mediterrane Archeologie 52, Groniningen, pp. 1-6.

Piranesi, G.B., 1756. Le antichità romane. Stamperia di Angelo Rotilj nel palazzo de' Massimi, Roma.

Portella, I.D., Ventre, F., 2004. The Appian Way: From Its Foundation to the Middle Ages. Getty Publications, Los Angeles.

Potenziani, M., Callieri, M., Dellepiane, M., Corsini, M., Ponchio, F., Scopigno, R. 2015. 3DHOP: 3D Heritage Online Presenter. Computers \& Graphics 52 129-141.

Renfrew, C., 1997. Foreword. In: Forte, M., Siliotti, A. (Eds.), Virtual Archaeology: Recreating Ancient Worlds. Harry Abrams, New York, p. 7.

Schäfer, A., Bocka, G., Sandayb, J., Leittea, H., 2015. Virtually reassembling Angkorstyle Khmer temples. Digital Applications in Archaeology and Cultural Heritage, 2-11, Elsevier.

Serlorenzi, M., De Tommasi, A., 2010. S.I.T.A.R. - Sistema Informativo Territoriale Archeologico di Roma, A repository of archaeological data for conservation of cultural heritage and town planning. In: Proceeding of 15th International Conference on "Cultural Heritage and New Technologies", Vienna. (272-282).

Von Schwerin, J., Richards-Rissetto, H., Remondino, F., Agugiaro, G., Girardi, G., 2013. The MayaArch3d project: a 3D WebGIS for analyzing ancient architecture and landscapes. Literary and Linguistic Computing 28 (4). http://dx.doi.org/ 10.1007/s10816-014-9226-7.

Von Schwerin, J., Richards-Rissetto, H., Remondino, F., Spera, M.G., Auer, M., Billen, N., Loos, L., Stelson, L., Reindel, M., 2016. Airborne LiDAR acquisition, postprocessing and accuracy-checking for a 3D WebGIS of Copan, Honduras. Journal of Archaeological Science: Reports 5 (2016), 85-104, Elsevier.

Zocchi, A., 2009. Via Appia: cinque secoli di immagini: un racconto da Porta San Sebastiano al IX miglio. "L'Erma" di Bretschneider, Roma.

\section{Websites}

URL 1: 〈http://www.mayaarch3d.org/language/en/sample-page/〉 (accessed 11.01.16).

URL 2: 〈www.mappingtheviaappia.nl〉 (accessed 31.08.15).

URL 3: 〈www.github.com $\rangle$ (accessed 31.08.15).

URL 4: 〈http://www.drive-map.eu/ (accessed 31.08.15)

URL 5: 〈https://github.com/NLeSC/structure-from-motion〉 (accessed 31.08.15).

URL 6: 〈https://github.com/NLeSC/bundler_sfm〉 (accessed 31.08.15).

URL 7: 〈https://github.com/NLeSC/CMVS-PMVS〉 (accessed 31.08.15).

URL 8: 〈https://github.com/NLeSC/PattyAnalytics〉 (accessed 31.08.15).

URL 9: 〈http://www.openscenegraph.org/〉 (accessed 31.08.15).

URL 10: $\langle$ http://potree.org/wp/ $\rangle$ (accessed 31.08.15).

URL 11: 〈https://github.com/NLeSC/PattyData〉 (accessed 31.08.15).

URL 12: 〈https://github.com/NLeSC/PattyVis〉 (accessed 31.08.15). 
URL 13: 〈http://geoplaza.vu.nl/cms/〉 (accessed 31.08.15).

URL 14: 〈http://www.opengeospatial.org/domain/built〉 (accessed 31.08.15).

URL 15: 〈http://www.3dhop.net/〉 (accessed 31.08.15).

URL 16: 〈http://www.w3.org/〉 (accessed 11.01.16).

URL 17: 〈www.londoncharter.org/〉 (accessed 17.12.15).
URL 18: 〈http://www.dans.knaw.nl/en $\rangle$ (accessed 11.01.16).

URL 19: 〈http://3dicons-project.eu/ (accessed 31.08.15)

URL 20: 〈http://ariadne-infrastructure.eu/〉 (accessed 31.08.15)

URL 21: 〈http://ahn2.pointclouds.nl〉 (accessed 11.01.16). 